Background: Human peripheral blood mononuclear cells (PBMC) left in microcultures for $24 \mathrm{~h}$ without mitogen do not respond to subsequent stimulation with PHA. They regain reactivity if the native culture medium is absorbed with other party lymphocytes or partially replaced with the medium from a PHAstimulated culture. The observations suggest that, during the incubation, some inhibitory agent had accumulated in the culture medium.

Aim: The study was performed to determine the nature of the observed phenomenon in respect of the possible role of monocytes and their products IL-1 and IL-1 receptor antagonist (IL-1ra), and to test for immunodiagnostic purposes the significance of quantifying the lymphocyte response to delayed stimulation with PHA in patients suffering from inflammatory prosesses.

Methods: Lymphocyte response to delayed stimulation with PHA, calculated as the lymphocyte-monokine interaction (LM) index, was determined in the microcultures of PBMC isolated from the blood of healthy donors or of patients with acute tonsilitis. The values of $L M$ indices were compared with the ratios of IL-1ra/IL-1 $\beta$ concentration estimated by enzyme-linked immunosorbent assay method in the culture supernatants. The influences of exogenous IL$1 \beta$, IL-1ra, anti-IL1ra antibodies and antibiotic cefaclor on the monokine concentrations and on the values of $L M$ index were tested.

Results and conclusions: The results show that the level of lymphocyte response to delayed stimulation with PHA (LM index) is inversely proportional to the ratio of IL-1ra/IL-1 $\beta$ concentration in the culture. The low $L M$ values at high $\mathrm{IL}-1 \mathrm{ra} / \mathrm{IL}-1 \beta$ ratios in PBMC cultures from healthy donors, reversed proportions found in patients' PBMC (acute tonsilitis), and the cefaclor-induced reduction of $L M$ value with correlated increase of the IL-1ra/IL-1 $\beta$ ratio suggest that the LM assay may prove to be useful for immunodiagnostic purposes.

Key words: IL-1 $\beta$ and IL-1ra competition, Delayed response to mitogen, LM assay - prognostic significance?

\section{Competition of IL-1 and IL-1ra determines lymphocyte response to delayed stimulation with PHA}

\author{
Marek P. Dąbrowski ${ }^{1, C A}$, Wanda Stankiewicz ${ }^{1}$, \\ Tadeusz Płusa ${ }^{2}$, Andrzej Chciałowski ${ }^{2}$ and \\ Stanisław Szmigielski ${ }^{1}$
}

${ }^{1}$ Military Institute of Hygiene and Epidemiology, Department of Microwave Safety, Immunology Laboratory, 00909 Warsaw, Szaserów 128, Poland; ${ }^{2}$ Central Clinical Hospital of Military Medical Academy, Clinic of Pneumonology and Allergy, Warsaw, Poland

\footnotetext{
${ }^{\mathrm{CA}}$ Corresponding Author

Tel: (+48) 226826122

Fax: (+48) 228104391

E-mail: szmigielski@wihe.waw.pl
}

\section{Introduction}

Phagocytosis, digestive processing, and presentation of antigen in complexes with self-histocompatibility molecules, supported by expression of additional immunogenic signals (including monokines, prostaglandins and oxidative radicals), collectively determine the participation of monocytes in the induction of specific immune responses and their concomitant contribution to development and maintenance of immunogenic tissue inflammation. One of the most potent immuno-enhancing members of the monokine family is interleukin-1.,2 To exert its immunostimulatory and pro-inflammatory effects, IL-1 has to compete with the other monocyte product, monokine IL-1 receptor antagonist (IL-1 ra), for access to its receptors on the surface of the target cell. In contrast to IL-1, IL-1ra is unable to transduce the stimulatory signal; thus, in binding to the receptor, the IL-1ra prevents its activation. ${ }^{3-5}$

Assessments of alterations in the IL-1 ra/IL-1 concentration ratio within the humoral environment of responding cells may provide clinically important information on the stage of the ongoing immune response and on the progression of the inflammatory process. In general, the lower values of the IL-1 ra/IL-1 ratio characterise the developmental phase, whereas 
increased values mark the termination of the both processes. $^{6-9}$

The IL-1 ra/IL-1 concentration ratio is measurable close to responding cells (in inflammatory tissue fluids) or at distant humoral peripheries (blood serum, spinal cord fluid, urine samples). In this respect, testing sites in the closest humoral vicinity can be expected to yield the most accurate information on the actual functional state of a cellular source of assessed monokines. Moreover, this goal may be gained by direct measurements of respective monokine concentrations (enzyme-linked immunosorbent assay (ELISA) method), or by estimation of the behaviour of other cells that are natural neighbours of monocytes and are primarily dependent on their monokine influence (e.g. the mitogenic proliferative response of $\mathrm{T}$ lymphocytes).

The mononuclear cell population isolated from peripheral blood and set-up in culture contains the quantity of monocytes and $\mathrm{T}$ cells representative of their respective blood values. Under appropriate experimental conditions, the results of tests performed on the cultures offer a possibility to obtain in vitro insight into the actual functional state of immune cells' in vivo, characteristic for the tested individual.

Other authors and ourselves ${ }^{10,11}$ have previously observed that human blood-derived mononuclear cells, if incubated in microcultures for $24 \mathrm{~h}$ without mitogenic stimulation, lose the capacity for proliferative response to subsequent stimulation with PHA, as can be demonstrated at $72 \mathrm{~h}$ by measurement of $\left[{ }^{3} \mathrm{H}\right]$-thymidine incorporation. Although the number and viability of cells remained undisturbed, any trials, including changes of PHA concentration (from suboptimal to overoptimal doses) or addition of exogenous IL-2, did not induce the proliferative response. Nevertheless, the cells could regain the reactivity if their native culture medium was partially replaced at $24 \mathrm{~h}$ with the cell-free medium from a PHA-stimulated culture or if part of it was separately absorbed with autologous lymphocytes and returned to the original cell culture before the stimulation.

These observations suggested that some inhibitory humoral agent had accumulated in culture medium during the $24 \mathrm{~h}$ of incubation, and that the level of lymphocyte reactivity regained upon subsequent stimulation with PHA is dependent on the concentration of the putative inhibitory agent.

The aim of the present experiments was to determine the nature of the observed phenomenon in respect of the possible role of monocytes and their products, IL-1 and IL-1ra, and to test for immunodiagnostic purposes the significance of quantifying the lymphocyte response to delayed stimulation with PHA in patients suffering from inflammatory processes.

\section{Materials and methods}

Peripheral blood mononuclear cells (PBMC) were isolated by density gradient sedimentation (Ficol/ Hypaque, $1.007 \mathrm{~g} / \mathrm{ml}$, Pharmacia LKB, Uppsala, Sweden) of heparinised venous blood samples taken from healthy donors or patients suffering from acute infections of the upper respiratory tract (both sexes, age range 20-40 years). After determination of cell viability, the microcultures were set-up in triplicate in Nuncoln round-bottomed 96-well microplates, as previously described. ${ }^{10}$ In brief, the cultures (each containing $10^{5}$ cells in $0.2 \mathrm{ml}$ of RPMI 1640 supplemented with $15 \%$ of inactivated autologous serum) were incubated at $37^{\circ} \mathrm{C}$ in an ASSAB incubator in a humified atmosphere of $5 \% \mathrm{CO}_{2}$ in air for $72 \mathrm{~h}$. In each experiment, several sets of triplicate microcultures were left without stimulation and others were stimulated at $0 \mathrm{~h}$ with PHA (HA16, $0.4 \mu \mathrm{g} /$ culture, optimal dose; Murex Biotech Ltd., Dartford, UK). For the last $16 \mathrm{~h}$ of incubation, $\left[{ }^{3} \mathrm{H}\right]$-thymidine (3HTdR) (specific activity, $5 \mathrm{Ci} / \mathrm{mM}$; Amersham, UK) was added into the cultures in a dose of $0.4 \mu \mathrm{Ci}$ per well. After harvesting the cultures, the measurements of incorporated radioactivity were carried out in a Tri-carb 2100 TR Packard liquid scintillation analyser and the results were expressed as a mean value of disintegrations per minute $(\mathrm{dpm}) \pm$ SD for each triplicate. Additionally, the volumes of $0.1 \mathrm{ml}$ of cell-free medium (CFM) were removed at $24 \mathrm{~h}$ from separate sets of triplicated non-stimulated cultures and replaced with equal volumes of CFM taken from PHA-stimulated cultures. The cultures rearranged on this way were further processed as already described and served for calculation of LM indices according to the formula:

\section{$\mathrm{LM}$ index $=$ \\ mean value of $\mathrm{dpm}$ in rearranged cultures \\ mean value of $\mathrm{dpm}$ in non-stimulated cultures}

We have decided to use this formula for the following reasons. The sparse cells in the PBMC population that 'spontaneously' incorporate $3 \mathrm{HTdR}$ in vitro have already entered in vivo the S phase of cell cycle and they do not participate in the response of other cells to the subsequent stimulation with mitogen. Under these circumstances, the simple subtraction of the values of radioactivity incorporated by the cells stimulated in entirely different ways does not seem to be well justified. On the contrary, the ratio of mitogen-stimulated to 'spontaneous' incorporation seems to provide adequate information on how many more cells have contributed to the observed total value of incorporated radioactivity.

Concomitantly, the samples of CFM removed at $24 \mathrm{~h}$ from non-stimulated cultures were frozen and 
Table 1. Effects of partial exchange of medium in cultures stimulated with PHA at $24 \mathrm{~h}$ of incubation

\begin{tabular}{|c|c|c|c|c|c|c|}
\hline \multicolumn{5}{|c|}{$\begin{array}{c}{\left[{ }^{3} \mathrm{H}\right] \text {-Thymidine incorporation into triplicate cultures }\left(\mathrm{dpm} \times 10^{3} \pm \mathrm{SD}\right)} \\
\text { measured at } 72 \mathrm{~h} \text { of incubation }\end{array}$} & \multicolumn{2}{|c|}{ Index } \\
\hline Experiment & $\begin{array}{l}\text { Not } \\
\text { stimulated }\end{array}$ & $\begin{array}{c}\text { Stimulated } \\
\text { with PHA at } \\
0 \mathrm{~h}\end{array}$ & $\begin{array}{l}\text { Stimulated } \\
\text { with PHA at } \\
24 \mathrm{~h} \text { without } \\
\text { change of } \\
\text { medium }\end{array}$ & $\begin{array}{c}\text { Stimulated } \\
\text { with PHA at } \\
24 \mathrm{~h} \text { after } \\
\text { partial exchange } \\
\text { of medium }^{\mathrm{a}}\end{array}$ & $\mathrm{PHA}^{\mathrm{b}}$ & $\mathrm{LM}^{\mathrm{c}}$ \\
\hline 1 & $1.8 \pm 0.10$ & $42.6 \pm 5.2$ & $2.2 \pm 0.6$ & $12.2 \pm 1.1$ & 23.7 & 6.8 \\
\hline 2 & $1.0 \pm 0.08$ & $31.2 \pm 4.1$ & $1.6 \pm 0.1$ & $16.2 \pm 2.2$ & 31.2 & 16.2 \\
\hline 3 & $1.6 \pm 0.05$ & $58.8 \pm 1.7$ & $2.4 \pm 0.2$ & $20.6 \pm 0.7$ & 36.7 & 12.9 \\
\hline 4 & $1.7 \pm 0.10$ & $71.3 \pm 5.3$ & $1.9 \pm 0.3$ & $8.4 \pm 1.3$ & 41.9 & 4.9 \\
\hline
\end{tabular}

${ }^{a}$ At $24 \mathrm{~h}$, half the volume $(0.1 \mathrm{ml})$ of cell-free medium was removed and replaced with $0.1 \mathrm{ml}$ of CFM from PHA-stimulated culture.

b PHA index $=(\mathrm{dpm}$ in cultures stimulated with PHA at $0 \mathrm{~h}) /(\mathrm{dpm}$ in non-stimulated cultures).

${ }^{c}$ LM index $=(\mathrm{dpm}$ in cultures stimulated with PHA at $24 \mathrm{~h}$ after the change of medium) / (dpm in non-stimulated cultures).

subsequently assessed quantitatively by ELISA for IL$1 \beta$ and IL-1ra content. The assessments were carried out in the universal microplate analyzer Elx800 (Biokom, Poland) with application of respective Quantikine kits (R\&D Systems, Abingdon, UK).

In one particular experiment, the combined CFM collected at $24 \mathrm{~h}$ from two sets of triplicated nonstimulated cultures $(0.6 \mathrm{ml}$ in total) was absorbed for $30 \mathrm{~min}$ with $10^{6}$ autologous lymphocytes and, after centrifugation, returned at $0.1 \mathrm{ml}$ per culture into one set of the original triplicated cultures. These were then stimulated with PHA and further processed as already described.

In consecutive experiments, separate sets of triplicated microcultures were treated at $0 \mathrm{~h}$ with $20 \mathrm{ng} / \mathrm{ml}$ recombinant human IL-1 $\beta$ (Genzyme, Cambridge, MA, USA), $20 \mathrm{ng} / \mathrm{ml}$ recombinant human IL-1ra (Serotec, Oxford, UK), $5 \mu \mathrm{g} / \mathrm{ml}$ anti-human IL-1 ra neutralising antibody (lot number Z05; R\&D Systems), or with $40 \mu \mathrm{g} / \mathrm{ml}$ pure soluble substance of cefaclor (Elli Lilly, Poland). These cultures were further processed as already described to assess the IL-1 ra/IL-1 $\beta$ concentration ratio and/or the LM index.
The results were statistically analysed using the Student $t$-test to estimate the significance of differences (at $p<0.05$ ). Correlations were determined by linear regression analysis.

\section{Results}

The viability of cells tested at the end of the cultures remained, in general, at the level of $80 \%$ of initial number of cells set in the culture. In several cases of lower cell viability obserbed at the end of the cultures, the results were dicounted.

Table 1 demonstrates results of representative experiments in which PBMC microcultures were routinely stimulated with PHA at $0 \mathrm{~h}$, left without stimulation for $24 \mathrm{~h}$, and then treated with the mitogen or stimulated with PHA at $24 \mathrm{~h}$ after partial exchange of culture medium. The cells responded well to routine mitogenic stimulation (range of response, $31.2 \pm 4.1 \times 10^{3}$ to $71.3 \pm 5.3 \times 10^{3} \mathrm{dpm}$ ), but did not respond at all if they were stimulated with PHA at $24 \mathrm{~h}$ (3HTdR incorporation remained at the level of spontaneous incorporation observed in

Table 2. Cultures preincubated for $24 \mathrm{~h}$ and then stimulated with PHA: effects of partial absorption of culture medium (cell-free medium (CFM)) with autologous lymphocytes

\begin{tabular}{|c|c|c|c|c|}
\hline Cultures & Control & Procedure & Experimental & Procedure \\
\hline $0 \mathrm{~h}$ & $\cup \cup \cup$ & - & $\cup \cup U \cup \cup U$ & - \\
\hline $24 \mathrm{~h}$ & $\cup \cup \cup$ & $\Leftarrow+\mathrm{PHA} \Rightarrow$ & $\begin{array}{l}\Rightarrow \\
\Leftarrow\end{array}$ & $\begin{array}{l}\text { Half the volume of CFM }(6 \times 0.1 \mathrm{ml}) \text { removed, } \\
\text { absorbed for } 30 \mathrm{~min} \text { with } 10^{6} \text { lymphocytes and } \\
\text { volumes of } 0.1 \mathrm{ml} \text { of CFM returned to the first } \\
\text { triplicate of cultures }\end{array}$ \\
\hline $48 \mathrm{~h}$ & $\cup \cup \cup$ & $\Leftarrow+3 \mathrm{HTdR} \Rightarrow$ & $\cup \cup U \quad---$ & - \\
\hline $72 \mathrm{~h}$ & $1607 \pm 144 \mathrm{dpm}$ & $\begin{array}{l}\text { measurement } \\
\text { of } 3 \mathrm{HTdR} \\
\text { incorporation }\end{array}$ & $4188 \pm 16 \mathrm{dpm}$ & Statistical significance $(p<0.01)$ \\
\hline
\end{tabular}


Table 3. Cultures preincubated for $24 \mathrm{~h}$ and then stimulated with PHA: influence of supplementation with IL- $1 \beta$ (20 ng/ml) or IL$1 \mathrm{ra}(20 \mathrm{ng} / \mathrm{ml})$ on the values of LM indices

\begin{tabular}{|c|c|c|c|}
\hline \multicolumn{2}{|c|}{$\begin{array}{l}\text { Experiments in which a high response } \\
(\text { LM index }>6.0) \text { has been observed }\end{array}$} & \multicolumn{2}{|c|}{$\begin{array}{l}\text { Experiments in which a low response } \\
(\text { LM index }<6.0) \text { has been observed }\end{array}$} \\
\hline $\mathrm{IL}-1 \beta$ & IL-1ra & $\mathrm{IL}-1 \beta$ & IL-1ra \\
\hline 0.92 & 0.77 & 1.53 & 0.96 \\
\hline 1.35 & 0.63 & 2.23 & 1.19 \\
\hline 1.03 & 0.79 & 1.53 & 1.09 \\
\hline 1.05 & 0.51 & 3.68 & 1.18 \\
\hline 0.93 & 0.70 & 2.18 & 1.03 \\
\hline 1.20 & 0.61 & 2.03 & 1.01 \\
\hline 0.98 & 0.35 & 3.04 & 0.99 \\
\hline $\bar{x}=1.06 \pm 0.16$ & $\bar{x}=0.62 \pm 0.16$ & $\bar{x}=2.32 \pm 0.79$ & $\bar{x}=1.06 \pm 0.08$ \\
\hline
\end{tabular}

Data are the ratio of $\left[{ }^{3} \mathrm{H}\right]$-thymidine incorporation into the treated with monokine cultures and non-treated cultures

control cultures). After partial exchange of culture medium, the cells regained some ability to respond to delayed stimulation with PHA: their responses calculated as LM indices were considerably lower than, and did not relate directly to, the values of 'normal' response to PHA. The other way of rendering the unresponsive cells responsive to delayed stimulation was to treat part of the culture medium $(0.1 \mathrm{ml}$ from each of the cultures) to short absorption with autologous lymphocytes and then return it to the original microculture before stimulation with PHA. The results of respective experiments are presented in Table 2.

To determine the influence of chosen monokines on the response of PBMC to delayed stimulation with PHA, a series of experiments were performed in which cultures were supplemented with exogenous IL-1 $\beta(20 \mathrm{ng} / \mathrm{ml})$ or IL-1 ra $(20 \mathrm{ng} / \mathrm{ml})$. The results are presented in Table 3. As a mean value of $8.2 \pm 2.5$ of the LM index was found in the PBMC cultures of healthy donors (see Table 5), the breakeven point 6.0 has been arbitrarily chosen for further discerning between the low and the high LM values observed in PBMC cultures. The supplementation with IL-1 $\beta$ resulted in considerable increases in the LM values of cultures demonstrating a low level of reactivity (LM index $<6.0$ in control cultures) but did not change the LM values in cultures expressing higher levels of reactivity (LM index $>6.0$ in control cultures). Opposing effects were observed in cultures supplemented with IL-1ra. Low LM values did not change, but high LM values decreased significantly. The existence of this competitive influence of IL-1 ra and IL-1 $\beta$ on the response of lymphocytes to delayed stimulation with PHA, as expressed by LM values, has been confirmed in experiments involving application of neutralising anti-IL-1ra antibodies. Addition of antiIL-1 ra antibody in a dose of $5 \mu \mathrm{g} / \mathrm{ml}$ into the microcultures resulted, on average, in a twofold increase in the LM index. The results of respective experiments are presented in Table 4 .

In the next series of experiments (Fig. 1), performed on PBMC derived from 10 patients suffering from acute tonsillitis, the LM values and IL-1 ra/IL-1 $\beta$ concentration ratios were estimated for control microcultures and for microcultures treated with pure substance cefaclor $(40 \mu \mathrm{g} / \mathrm{ml})$. In the cultures treated with cefaclor, significant reductions in the values of the LM index were observed (mean values, $26.8 \pm 8.3$ for control cultures and $11.3 \pm 3.2$ for cefaclor treated

Table 4. Influence of anti-IL-1ra antibodies on $\left[{ }^{3} \mathrm{H}\right]$-thymidine incorporation $\left(\mathrm{dpm} \times 10^{3}\right)$ in cultures stimulated with $\mathrm{PHA}$ at $24 \mathrm{~h}$ of incubation

\begin{tabular}{lccrr}
\hline Experiment & Anti-IL-1ra & $\begin{array}{c}\text { Control } \\
\text { cultures }\end{array}$ & $\begin{array}{c}\text { Cultutres } \\
\text { stimulated } \\
\text { with PHA }^{\text {a }}\end{array}$ & $\begin{array}{c}\text { LM } \\
\text { index }\end{array}$ \\
\hline 1 & - & $0.9 \pm 0.01$ & $15.5 \pm 0.5$ & 17.2 \\
& + & $1.7 \pm 0.20$ & $59.6 \pm 4.4$ & 35.1 \\
3 & - & $1.1 \pm 0.20$ & $18.2 \pm 0.6$ & 16.5 \\
3 & + & $1.0 \pm 0.06$ & $35.2 \pm 2.8$ & $8.1 \pm 1.5$ \\
4 & + & $1.0 \pm 0.07$ & $14.5 \pm 1.8$ & 8.1 \\
& - & $1.2 \pm 0.10$ & $4.3 \pm 0.4$ & 12.1 \\
& + & $1.1 \pm 0.10$ & $7.2 \pm 0.6$ & 3.9 \\
& $1.1 \pm 0.20$ & 6.5 &
\end{tabular}

${ }^{a}$ At $24 \mathrm{~h}$ of incubation, half the volume $(0.1 \mathrm{ml})$ of cell free medium was removed and replaced with $0.1 \mathrm{ml}$ of fresh medium with PHA. 

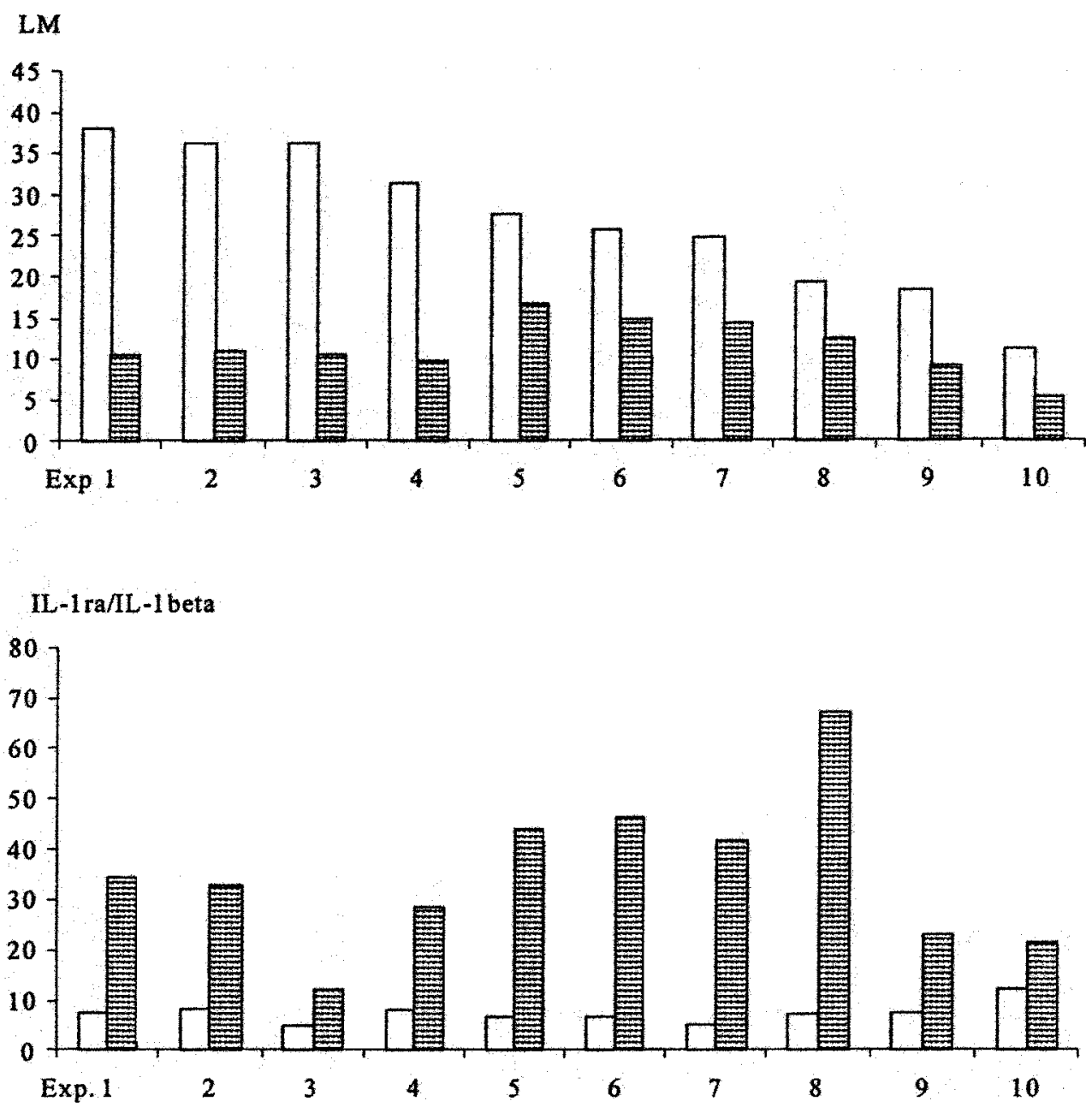

\section{$\square$ control Etreated with cefaclor}

FIG. 1. Values of LM indices depend on the ratio of IL-1ra/IL-1 $\beta$ concentration in peripheral blood mononuclear cell microcultures treated with cefaclor.

cultures; $p<0.01$ ), and these changes were well correlated $\left(r^{2}=0.81\right)$ with the changes of the values of IL-1 $\mathrm{ra} / \mathrm{IL}-1 \beta$ concentration ratio (mean values, $7.5 \pm$ 2.3 for control cultures and $35.1 \pm 16.9$ for cultures treated with cefaclor; $p<0.01$ ).

The results presented in Table 5 compare the LM values, the IL-1 $\beta$ and IL-1 ra concentrations, and the IL$1 \mathrm{ra} / \mathrm{IL}-1 \beta$ concentration ratios observed in micro- cultures of PBMC from healthy donors and from patients with acute inflammation of the upper respiratory tract. The mean value of LM indices observed in the group of patients $(18.4 \pm 5.8)$ was significantly higher than the respective value in the group of healthy donors $(8.2 \pm 2.5)$. The mean value of the IL$1 \beta$ concentration in the patients' PBMC cultures $(633.8 \pm 244.5 \mathrm{pg} / \mathrm{ml})$ was also considerably higher

Table 5. LM values, IL-1 $\beta$, IL-1ra concentrations $(\mathrm{pg} / \mathrm{ml}$ ) and IL-1ra/lL-1 $\beta$ concentration ratios in microcultures of peripheral blood mononuclear cells (PBMC) from healthy donors and from patients with acute infections of the upper respiratory tract

\begin{tabular}{|c|c|c|c|c|}
\hline \multirow[t]{2}{*}{ PBMC microcultures from: } & \multicolumn{4}{|c|}{ Mean value $\pm S D$} \\
\hline & LM index & IL-1 $\beta$ & IL-1ra & IL-1ra/IL-1 $\beta$ \\
\hline $\begin{array}{l}\text { Healthy donors }(n=20) \\
\text { Patients }(n=20) \\
\text { Statistical significance, } p\end{array}$ & $\begin{array}{r}8.2 \pm 2.5 \\
18.4 \pm 5.8 \\
<0.01\end{array}$ & $\begin{array}{l}170 \pm 90 \\
630 \pm 240 \\
<0.01\end{array}$ & $\begin{array}{l}1900 \pm 810 \\
2560 \pm 915 \\
\text { NS }\end{array}$ & $\begin{aligned} & 11.1 \pm 7.5 \\
& 4.0 \pm 1.8 \\
&<0.05\end{aligned}$ \\
\hline
\end{tabular}


than in cultures of healthy donors' PBMC (167.75 \pm $89.5 \mathrm{pg} / \mathrm{ml}$ ). The IL-1 ra concentrations were high in healthy donors' $(1867.25 \pm 806.5 \mathrm{pg} / \mathrm{ml})$ as well as in patients' PBMC cultures $(2559.31 \pm 914.7 \mathrm{pg} / \mathrm{ml})$, and did not represent statistically significant differences. The calculated IL-1ra/IL-1 $\beta$ concentration ratio was significantly higher for healthy donors $(11.13 \pm 7.5)$ than for the patients $(4.03 \pm 1.76)$.

\section{Discussion}

Since Mitchison's classic 'three mouse experiment'12 demonstrating T-cell, B-cell and macrophage cooperation in development of the immune response, the immunogenic role of monocytes and other antigen presenting cells (APC) has been extensively investigated and become well recognised.,2,13-14 Antigen presentation is an immunogenic as a complex with self-histocompatibility molecules (MHC class II antigens). This permits the APC (monocytes, macrophages or dendrytic cells) to recruit from the polyclonal pool of immunocompetent $\mathrm{T}$ cells the helper-inducer TCD4+ lymphocyte representing a clonal specificity complementary to the presented antigen. Further development of a specific immune response greatly depends on the quality and quantity of additional co-stimulatory signals from the APC whereby they modulate the behaviour of responding cells, ${ }^{16-18}$

In the large repertoire of APC products, there are two possessing distinguishable potential to regulate the proliferative phase of the T-lymphocyte response. One is IL-1, already known for its multiple immunoenhancing and pro-inflammatory effects, ${ }^{1,2}$ and the other (the more recently recognised IL-1ra) is a natural inhibitor of the former. ${ }^{18-20}$

The population of PBMC contains both APC (monocytes) and $\mathrm{T}$ lymphocytes in quantities and with typical functional properties characteristic for the donor. The inactive lymphocytes remaining at the $G_{o}$ stage of their cell cycle do not spontaneously produce any cytokine until reception of mitogenic stimulation. The monocytes, however, produce in vitro the monokine repertoire representative of their in vivo activity. ${ }^{8}$ Thus, assessment of the level of proliferative response of $\mathrm{T}$ cells co-cultured with monocytes and exposed to their influence prior the mitogenic stimulation should supposedly indicate which of the competitive monokines, IL-1ra or IL-1, is currently gaining the functional preponderance over the competitor. This, in turn, may serve to characterise the actual functional state of the monocytes in question, and, in so doing suggests a role for the use of $\mathrm{T}$ lymphocytes as indicator cells.

The results of our experiments on PBMC have confirmed the dependence of the T-lymphocyte response to delayed stimulation with $\mathrm{PHA}$ on the proportion of IL-1ra and IL-1 $\beta$ produced by the monocytes into the culture medium before mitogenic stimulation. Non-responding $\mathrm{T}$ cells appeared to regain their proliferative ability if the inhibitory influences of IL-1ra were reduced by partial exchange of the medium, or by exposure of the medium to autologous lymphoctes, or by the addition to the culture of anti-IL-1ra antibodies.

The level of regained reactivity, given as the LM value that did not relate to the level of 'normal' response to PHA, also did not correlate directly with the concentration of IL-1 $\beta$ or IL-1 ra found in the culture medium, but it did appear to correlate with the changes of IL-1 ra/IL$1 \beta$ concentration ratio. The cultures supplemented with the exogenous IL-1 $\beta$ demonstrated increased LM values if control LM values were low $(<6.0)$ but not if they were high ( $>$ 6.0). Conversely, addition of exogenous IL-1 ra decreased the high LM values but did not change the low LM values. The results seem to reflect the effects of competition between the added and endogenous IL-1ra and IL-1 $\beta$ for access to IL-1 receptors on target cells.

The next series of experiments were performed to evaluate the possibility of application of the LM index assessments for clinical diagnostic purposes. The cultures of PBMC from 10 patients suffering from acute tonsilitis were set-up and tested for this, as well as for the values of IL-1ra/IL-1 $\beta$ concentration ratio under in vitro influence of cefaclor, the antibiotic usually administered in vivo for treatment of the disease. In vitro addition of cefaclor resulted in significant increase of IL-1 ra/IL-1 $\beta$ concentration ratio (from $7.5 \pm 2.3$ to $35.1 \pm 16.9$ ) and in correlated decrease of $\mathrm{LM}$ values (from $26.8 \pm 8.3$ to $11.3 \pm 3.2$ ). The close correlation of the changes in the two parameters suggests that assessment of the LM index in PBMC cultures may serve as a suitable and inexpensive test for evaluation of the monocyte immunogenic activity. The suggestion has received further confirmation from the results of assessments of LM values and IL- $1 \mathrm{ra} / \mathrm{IL}-1 \beta$ concentration ratios performed on cultures of PBMC from healthy donors $(n=20)$ and from patients with acute or exacerbated upper respiratory tract infections $(n=20)$. The results presented in Table 5 show that the mean LM index value representative for the healthy donor's group $(8.2 \pm 2.5)$ is significantly lower than the respective value observed in the patients' group $(18.4 \pm 5.8)$ and, reciprocally, the IL-1 ra/IL-1 $\beta$ concentration ratio is considerably higher in the healthy donors' PBMC cultures $(11.13 \pm 5.51)$ than in the patients' PBMC cultures $(4.03 \pm 1.76)$. In the patients' PBMC cultures, both the IL-1 $\beta$ and IL-1ra concentrations were higher than in the healthy donors' cultures, but a relatively high IL-1 $\beta$ concentration appeared to be mainly responsible for the observed diminution in IL-1ra/IL$1 \beta$ ratio.

In conclusion, the proposed modification of procedure based on delayed stimulation with PHA and 
appropriate pre-arrangements of the culture medium in human PBMC microcultures seems to offer a relatively simple and inexpensive method for conveniently assessing monocyte immunogenic activity. The method of LM assay would appear to be prospectively useful for diagnostic evaluation of monocyte influence on the development of tissue inflammatory processes and on the lymphocyte proliferative response. Supposedly, the LM assay may also find application in clinical monitoring of the potency of different immunotropic drugs for influencing the monocyte functional state.

\section{References}

1. Oppenheim JJ, Kovacs EJ, Matsushima K, Durum SK. There is more than one interleukin-1. Immunol Today 1986; 7: 45-56.

2. Kaye J, Janeway CA Jr. Induction of receptors for interleukin 2 requires T cell Ag: Ia receptor crosslinking and interleukin 1. Lymphokine Res 1984; 3: 175-182

3. Dripps DJ, Brandhuber BJ, Thompson RC, Eisenberg SP. Interleukin-1 (IL1) receptor antagonist binds to the $80-\mathrm{kDa}$ IL-1 receptor but does not initiate IL-1 signal transduction. J Biol Chem 1991; 266: 10331-10336.

4. Granowitz EV, Clark BD, Mancilla J, Dinarello CA. Interleukin-1 receptor antagonist competitively inhibits the binding of interleukin-1 to the type II interleukin-1 receptor. J Biol Chem 1991; 266: 14147-14150.

5. Eisenberg SP, Evans RJ, Arend WP, et al. Primary structure and functional expression from complimentary DNA of a human interleukin-1 receptor antagonist. Nature 1990; 343: 341-346.

6. Higuchi T, Yamamoto C, Kuno T, Mizuno M, Takahashi S, Kanmatsuse K Increased production of interlekin-1 receptor antaginist by peripheral blood mononuclear cells in undialyzed chronic renal failure. Nephron 1997; 76: 26-31.

7. Dana MR, Yamada J, Streilin JW. Topical interleukin 1 receptor antagonist promotes corneal transplant survival. Transplantation 1997; 63: 1501-1507.
8. Donati D, Degiannis D, Mazzola E, et al. Interleukin-1 receptors and receptor antagonists in haemodialysis. Nephrol Dial Transplant 1997; 12: $111-118$

9. Dinarello CA. The role of the interleukin-1-receptor antagonist in blocking inflammation mediated by interleukin-1. N Engl J Med 2000; 343: $732-734$.

10. Lindahl-Kiessling $\mathrm{K}$, Mattson A, Skoog V, Weber T. Is the induction of mitotic activity with Con A a two site as well as a two step procedure? In: Daguillard F, ed. Proceedings of the Seventh Leucocyte Culture Conference. New York: Academic Press, 1973:163-169.

11. Dabrowski MP, Dabrowska-Bernstein BK, Stasiak A, Gajkowski K, Korniluk S. Immunologic and clinical evaluation of multiple sclerosis patients treated with corticosteroids and/or calf thymic hormones. Ann NY Acad Sci 1987; 496: 697-706.

12. Mitchison NA. The carrier effect in the secondary response to haptenprotein conjugates. II. Cellular cooperation. Eur J Immunol 1971; 1 18-27.

13. Mizel SB, Farrar JJ. Revised nomenclature for antigen-nonspecific $T$ cell proliferation and helper functions. Cell Immunol 1979; 48: 433-437.

14. Beller DI, Unanue ER. Reciprocal regulation of macrophage and $T$ cell function by way of soluble mediators. Lymphokines $1982 ; 6: 25-30$

15. Mizel SB. Interleukin-1 and T cell activation. Immunol Rev 1982; 63 51-56.

16. Garcia KC, Teyton L, Wilson IA. Structural basis of T cell recognition. Ann Rev Immunol 1999; 17: 369-397.

17. Joseph SB, Miner KT, Croft M. Augmentation of naive, Th1 and Th2 effector CD4 responses by IL-6, IL-1 and TNF. Eur J Immunol 1998; 28 277-289.

18. Mire-Sluis AR, Thorpe R, eds. Cytokines. San Diego, CA: Academic Press, 1998.

19. Seckinger P, Lowenthal JW, Williamson K, Dayer J-M, MacDonald HR. A urine inhibitor of interleukin 1 activity that blocks ligand binding. $J$ Immunol 1987; 139: 1546-1549.

20. Mazzei GJ, Seckinger PL, Dayer JM, Shaw AR. Purification and characterization of a 26-kDa competitive inhibitor of interleukin-1. Eur J Immunol 1990; 20: 686-689.

Received 14 March 2001;

Accepted after revision 4 April 2001 


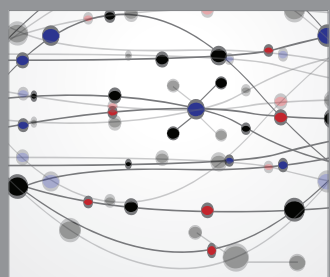

The Scientific World Journal
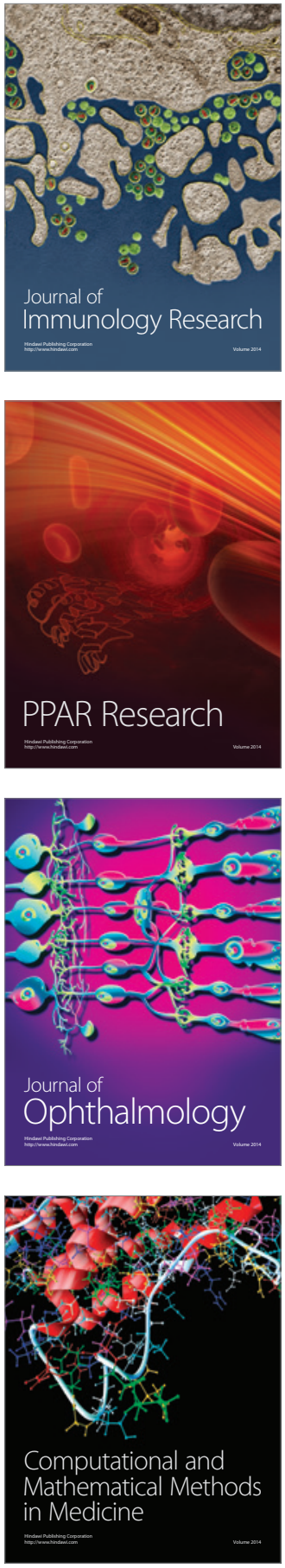

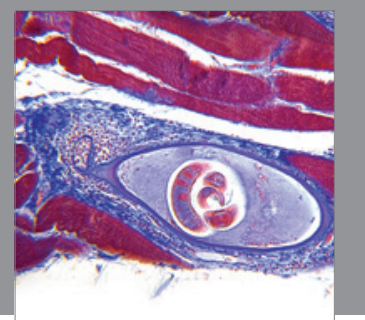

Gastroenterology

Research and Practice
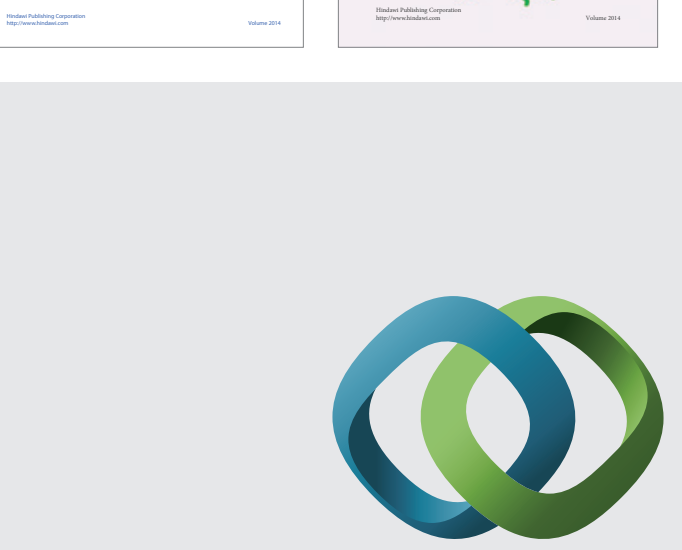

\section{Hindawi}

Submit your manuscripts at

http://www.hindawi.com
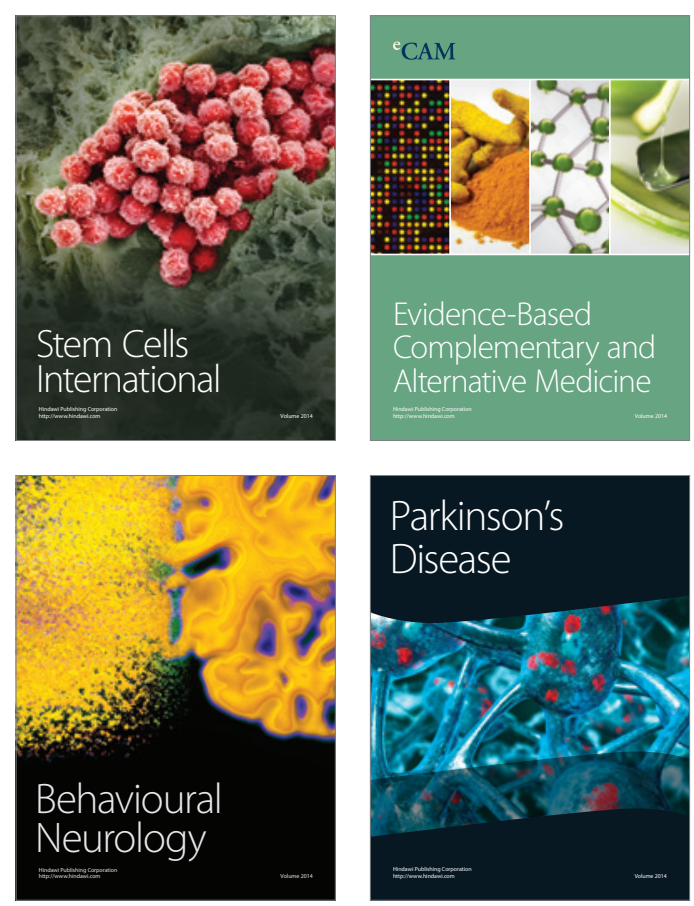

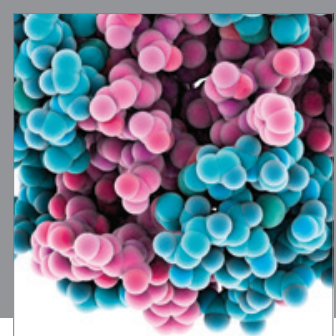

Journal of
Diabetes Research

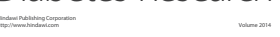

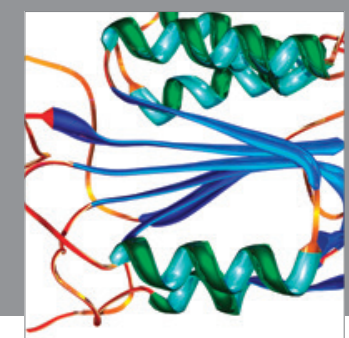

Disease Markers
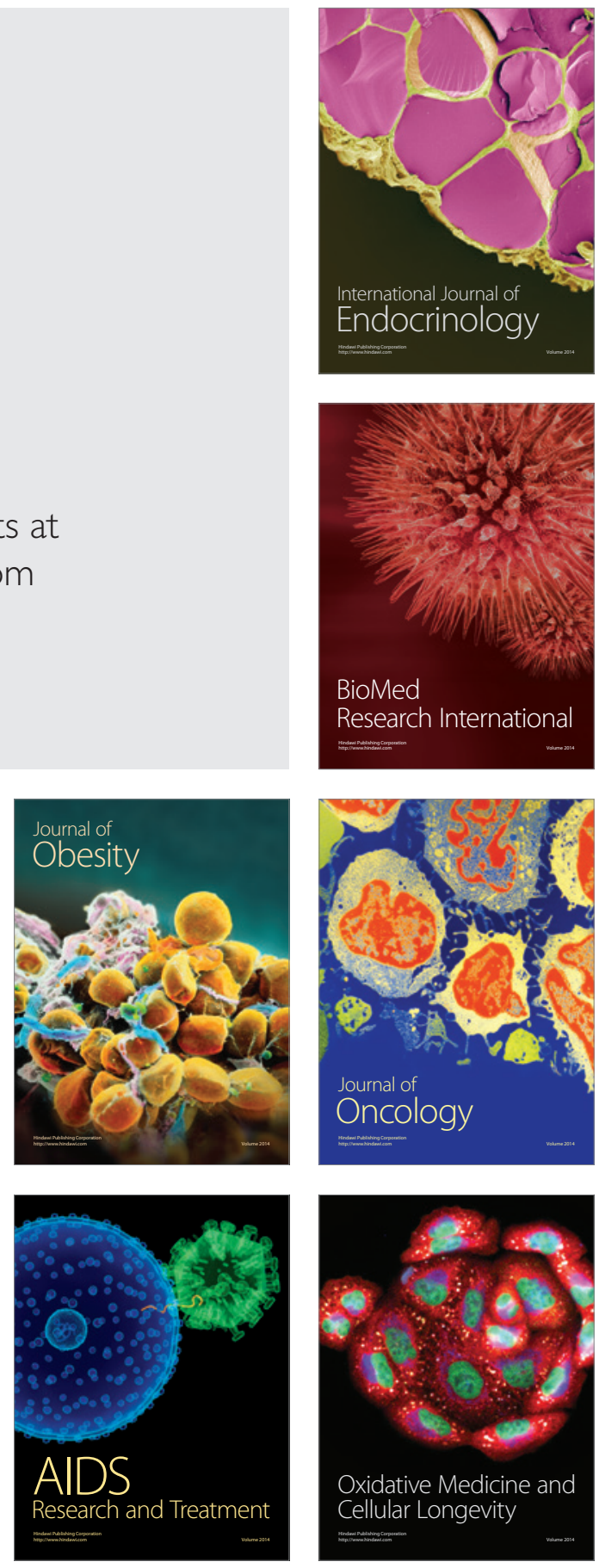